Article

\title{
Variants of Interplay as Drivers of Media Change
}

\author{
Tilo Grenz ${ }^{1, *}$ and Paul Eisewicht ${ }^{2}$ \\ ${ }^{1}$ Department of Sociology, University of Vienna, 1090 Vienna, Austria; E-Mail: tilo.grenz@univie.ac.at \\ 2 Department of Sociology, TU Dortmund University, 44221 Dortmund, Germany; E-Mail: paul.eisewicht@tu-dortmund.de \\ * Corresponding author
}

Submitted: 31 March 2017 | Accepted: 26 July 2017 | Published: 22 September 2017

\begin{abstract}
This article conceptualizes acting on media in terms of different interplays between focal actors, users, and user communities. It is argued that-in times of mediated visibility, the increasing entanglement of social and technological change, and accelerated feedback loops - arenas of negotiation emerge and therewith the complexities of relations between producers and users increases. Using insights from the fields of Wii hacking, Circuit Bending, and online poker tools, three variants of interplay are presented and discussed: integration, segregation, and permanent confrontation. Whilst a process-oriented perspective on reciprocal action is developed the paper contributes (a) to a balanced perspective on what is often a onesided discussion regarding the actions leading to media change, and (b) to the understanding of the relation between media change and reflexive modernity.
\end{abstract}

\section{Keywords}

acting on media; digital infrastructures; feedback loop; hacking; interplay; mediated construction of reality; outlaw innovation; reflexive modernity; side-effects; unmanageable consumer

Issue

This article is part of the issue "Acting on Media: Influencing, Shaping and (Re)Configuring the Fabric of Everyday Life", edited by Sigrid Kannengießer and Sebastian Kubitschko (University of Bremen, Germany).

(C) 2017 by the authors; licensee Cogitatio (Lisbon, Portugal). This article is licensed under a Creative Commons Attribution 4.0 International License (CC BY).

\section{Introduction and Framing: Acting on Media as a Result of Interplays}

Acting on media is intended to be a critique of the narrow focus in media and communication studies, on what people are doing whilst using media. It broadens the analytical focus and includes the "efforts of a wide range of actors to take an active part in the molding of the media organizations, infrastructures, and technologies" (Kannengießer \& Kubitschko, 2016). Studies with such a broad perspective cover e.g. citizen's critique of media organizations, hacker movements and their influence on security infrastructures or the economic potential of pioneer communities. Since these approaches are not limited to isolated features of media but emphasize the interests of people in order to induce cultural changes, acting on media can best be described as some kind of institutional work. Institutional work describes "the purposive action of individuals and organizations aimed at cre- ating, maintaining and disrupting institutions" (Lawrence \& Suddaby, 2006, p. 215). On the one hand, we follow this perspective in the socio-technical change which people intentionally and unknowingly induce. On the other hand, we draw on the recent shift towards a process-oriented analysis in media and communication studies (Couldry \& Hepp, 2017; Grenz \& Kirschner, in press). We want to join these approaches and focus on the variants of interplay between change-inducing actors. We argue that acting on media opens up the perspective on explicit forms of institutional work (as e.g. driven by "collectives of media change", Couldry \& Hepp, 2017, p. 180). This allows us to shed some light on the subtleties which exist between opposing views which prefer political counteracting on one hand and consensual media development on the other.

In order to do so, two assumptions have to be made: First, a process-oriented approach takes into account the-often frictional-interplay between different actors, since "all social systems are sediments of a history 
of voting, decree, conflict, agreement, compromise, bargaining, persuasion, coercion, and other forms of interaction, by which humans seek to achieve their interests and legitimate their perspectives" (Barley, 2008, p. 500). Second, as we will show, this perspective exceeds other approaches which tend to take an isolated and one-sided stance on action while neglecting the inter-active logic of evolving processes. Hence, an analytical vocabulary is needed that helps to understand the reciprocal actions and interactions of actors as variants of entanglements emerging over time.

Media, as socially embedded in and by communicative action (Knoblauch, 2017; Krotz, 2017), is anchored in its capacity of mediation. In a wider understanding, media has shaped and is shaping cultural objects that mediate different actor's actions-i.e. people and groups of people with culturally derived motives and expectations-and their meaningful and meaningindicating actions (Schütz \& Luckmann, 1973). Because objects can be intentionally modified and thereby can serve as a carrier of subjective expressions they can be seen as media. Hence, our focus is not just on specific objects but on people's creative practices towards and through media objects. However, in a more conventional understanding, these actions on media (objects) are always moderated by presentational processes that accompany these actions, enabled by distribution media. Put simply, activities and their results are-deliberately or accidentally-shared via multi-modal settings of today's media (Couldry, 2008).

By now, digital media, based on complex social and technological infrastructures, have become a materialized indication of ever growing arenas of controversies, frictions, and negotiations between different kinds and groups of actors. With this in mind, we shall continue with a recap of dominant positions, when focusing acting on media (chapter 2). Coming from that, three vignettes and related trajectories are presented (Wii hacking, Circuit Bending, online poker tools) (chapter 3). From these cases, we reconstruct three different variants of interplay between users, user communities, and producers: integration, segregation and permanent confrontation (chapter 4). We go on to connect the insights to the discussion on non-intended side-effects and reflexive modernization. Hereby, we particularly focus on permanent confrontations as being an increasingly symptomatic driver of de-stabilization in present-day societies as these are heavily based on digital ecosystems and accelerated feedback loops. However, we argue, that levels of interplay depend on specific factors, as not every action on media becomes relevant for the socio-technical and socio-economic fabric of everyday life.

\section{Stories of Harmony and Conflict: Beyond Dualistic Views}

With O'Reilly's (2005) introduction of the term "Web 2.0" for the field of internet economy, a shift occurred within service sciences. While product development in the last hundred years was characterized by a producer's "push", economy now shifted towards a logic of "pull" (Brown \& Hagel, 2005). Basically, this meant a broadened recognition and inclusion of the manifold consumer activities. Subsequently, Vargo and Lusch (2006) proclaimed a "service dominant logic". In a service dominant logic, providers, as well as users, collaborate side-by-side in order to develop and maintain products and services. This coincides with an opening-up of innovation processes that is discussed within innovation studies (Chesbrough, 2003). Technology development should no longer be allocated solely within the narrow boundaries of companies, but should flourish within open networks of different actors outside of firms. All these studies share the implicit assumption of a frame of reference, where users and doers, customers and providers, consumers and producers are related to each other via cooperation and consensus. In other words, each party expects and gains benefits from this harmonious relationship.

Other approaches emphasize more conflictual relations between producers and users, where motives of actors and groups diverge and asymmetrical power relations are contested. Technological and media change is thereby an ongoing struggle between powerful economic organizations and creative and rebellious users and citizens. These approaches argue for a more bottomup perspective on media, as being an object of engagement. The most prominent example is "hacker cultures", where a differentiation between "white-hat" hackers and "black-hat" hackers is made (Lievrouw, 2006, p. 118). For example, the Chaos Computer Club is "one of the world's largest (and Europe's oldest) hacker organizations (which is) countering contemporary surveillance assemblages" (Kubitschko, 2015, p. 85). Without question, notorious media movements, social movements, hacker movements, product-oriented movements as well as recently focused "media-related pioneer communities" (Hepp, 2016) differ in terms of their confrontational character, their social structures, and their audiences (Schäfer, 2009). However, the approaches of the rebellious users all share the politically-driven or interestdriven idea regarding users' core convictions (Hess, 2005; for a condensed overview: Couldry \& Hepp, 2017, pp. 180ff.). That is, that they contest common political and economic views of producers and providers.

One approach which is not limited to a perspective of congruence or opposition is that of Thomas P. Moran (2002). With the various failure-stories within software development in mind, Moran calls for a new understanding of development as a "negotiated social process" (Moran, 2002). His "everyday adaptive design"-approach is regarded as common sense within IT-engineering (Carroll \& Fidock, 2011; Dix, 2007; Fidock \& Carroll, 2006). More recently, specific interplays of appropriation, provision, and production are understood as "outlaw innovation" (Flowers, 2008). In regard to computer game modding, adware, spyware and file sharing, Stephen Flowers 
illustrates the tremendous influence of bypassing and modification activities on media technological innovation and further development. He argues that most of the digital information and communication media of today cannot be traced back to research and development within firms. Therefore, the idea of the solitary, visionary and successful entrepreneur seems as outdated as the harmoniously framed co-development. Rather, Flowers focuses on user activities that modify the features of a product in a way that the former intentions of the original designers are distorted, design flaws which are used in order to circumvent security systems, as well as the creation of software-based systems or services with dubious legality (Flowers, 2008, p. 178): "These activities may violate intellectual property and pose a direct threat to established suppliers with the result that the work will often be underground in nature, operating either anonymously or with those involved seeking to obscure their links to such activities. Within this milieu, innovations will emerge from non-cooperative, non-consensual relationships in which the user may be unknown to the supplier and in which there is likely to be no free flow of information between the two parties". This more or less goes in line with Schäfer's (2009) discussion of "user activities between design and appropriation", and the resulting paradigm shift from the passive reception of users to the "participatory" activities of users.

Rather than describing media and technological change as a one-way road of cooperation or confrontation, we suggest that acting on media should be viewed as a negotiation between dissimilarly powerful actors and groups who have different motivations. Characterising the trajectories of the interplay between these actors regarding their use of media helps to understand the various ways that successful and unsuccessful, intended and accidental cultural change can occur. By doing so, we contribute to the recently emerging research on today's media change from a process-perspective (Burgess \& Green, 2009; Grenz \& Kirschner, in press; Parikka, 2012).

One reason to include user actions in the analysis of media change is based on the possibilities of digital media to find, create and share knowledge easily with others beyond spatial, temporal and social boundaries. We follow Thompson's (2005, p. 35) diagnosis of mediated visibility, in which "the field of vision is stretched out in space and may also be stretched out in time: one can witness events occurring in distant places 'live', that is, as they occur in real time; one can also witness distant events which occurred in the past and which, thanks to the preservative qualities of the medium, can be represented in the present". In this way, the change of the very fabric of our everyday media saturated life happens in recourse to a plurality of realities as envisioned and enacted in different social groups. The ideas of these groups get into an accelerated flow of information diffusion and attention. As Thompson notes, these processes are not just information leakage but are also explicit strategies of actors that built on mediated visibility as "a weapon in the struggles they wage in their day-to-day lives" (Thompson, 2005, p. 31). At the same time, pervasive visibility also puts actors under pressure, as they are observable, observed and judged in regard to actions and events that they did not intend for the public.

However, the mediated visibility does not overturn the established asymmetrical power relations. In spite of early hopes, regarding the possibility for greater democracy, transparency, and equality in the media age, certain organizations still retain their authority. Organizations such as Alphabet (the parent company of Google), Apple, Facebook and other firms within the realm of an evolving digital market order (Kirchner \& Beyer, 2016) shape and provide products and services, structure communicative possibilities (Dolata, 2017), provide infrastructures and govern complex digital "ecosystems" (Tiwana, Konsynski, \& Bush, 2010). With a wider change within economic strategy, which has been described as a shift from push to pull, acting on media is a result of reciprocal actions of focal actors and other groups of actors.

The presentation (to make actions visible to a broader public) of users' actions (and the critique of producers) acts as a paragon of media tinkering for users as well as producers. Others' creative use of media not only gains recognition by users but serves as an inspiration to test the limits of media technology by oneself (and to develop new commercial offers by the producers). Therefore, one has to take into account changes within the socio-technical order as rooted in the altered rulesets of the digital materiality of media (Grenz \& Kirschner, in press; van den Boomen, Lammes, Lehmann, Raessens, \& Schäfer, 2009). A direct interference of media capacities on social entanglements is channeled by media technological capacities itself. This line of argument is based on the "generativity" (Zittrain, 2006, p. 1980) of today's media technology since "generativity denotes a technology's overall capacity to produce unprompted change driven by large, varied, and uncoordinated audiences". Programmability, as well as the networked nature of pervasive media, indicates a wider change in societal rulemaking, as it happens on a "socio-technical" level (Lash, 2003, p. 54). A significant consequence of this transformation is the emergence of a multitude of "arenas" (Strauss, 1993, p. 225) that were not supposed to be opened for active audiences. However, these are spaces where motives of different actors, various interests, divergent resources and thereby different powerrelations collide.

\section{Relations and Interplays: Three Vignettes}

Regarding the broad discussion on media change, it seems to be an erroneous conclusion to define the interplay between producers and users in the media age as either solely harmonious or conflict-laden. Rather than attributing conflicts or cooperation between producers and users to media effects, they are types of social relations that are moderated (but seldom caused) by the 
media. Therefore, one has to differentiate between such interplays in order to contextualize the "complex processes of interaction between different groups of actors" (Couldry \& Hepp, 2017, p. 219, referring to Grenz, 2014) that are at the heart of media change. In the following paragraphs, we provide insights into three cases based on our research, in order to underpin a systematization of the interplays between media firms, third companies and appropriating users. The cases were sampled due to the variation in the complexity of the social figuration between users and producers (see Corbin \& Strauss, 1990, p. 421). As we will show, each case has distinct properties that affect the course of the interplay between producers and users. Identified variations between the cases then served as the starting point for our typification. The presented vignettes and "storylines" (Corbin \& Strauss, 1990, p. 112) are built upon selected segments and key incidents of "fateful" trajectories (Strauss, 1993, p. 53) in each field. Trajectories are "fateful...courses of action but also...interaction of multiple actors and contingencies that may be unanticipated and not entirely manageable" (Strauss, 1993, p. 53).

\subsection{Succeeding Integration: The Case of Wii Hacking}

In 2006, Nintendo released the Wii, a video game console which had a remote controller with motion-sensing capabilities. People now could control the action on the screen not just by pressing buttons on a controller, but also by moving the controller in front of the consoles sensor bar. This was possible due to an accelerometer, a gyroscope and an infrared sensor built into the nunchucklike controller. Like the child toys for the Circuit Benders, the Wii console, due to the advanced technology and the affordable pricing was not only used for the intended purpose of playing video games on a TV screen. People used the technology for hacks and developed a series of projects, using parts of the Wii and its controller. The most popular example of this were the projects by Johnny Chung Lee (johnnylee.net, see also wiimoteproject.com or wii-homebrew.com). In a series of YouTube tutorials and downloadable software, Lee, at that time a PhD student at the Carnegie Mellon University in Pittsburgh, presented several applications for the motion sensor technology from the Wii. This included a low-cost interactive whiteboard that supported up to four input devices ("pens") and a head tracking tool that transformed regular screens into a virtual reality display.

People like Lee experimented with reversed and modified parts of the equipment mainly to see what is possible with the commercial product but also in order to create new forms of entertainment and education. Lee's inexpensive Whiteboard-upgrading a beamer and a laptop to an interactive whiteboard costs around 50 Dollar-was used in schools long before such devices were widely distributed or affordable. Even today, an interactive whiteboard can cost up to 5,000 Dollars. Lee's hack is still used and promoted for its usage in schools on several websites and video platforms (e.g. wiki.zum.de/wiki/Wii_als_Whiteboard or autenrieths.de/links/schwabenboard.htm) and was discussed in several scientific articles (e.g. Liou \& Chang, 2014, p. 97; Wittke, Ebner, \& Kröll, 2013, pp. 29f.; Yucel, Orhan, Misirli, Bal, \& Sahin, 2010, p. 149). Because of the enormous exposure of these projects, Lee was hired by Microsoft in order to develop their motion sensor controller ("Kinect") in 2010. He is currently working at Google's Project Tango (an augmented reality computing platform).

Lee's case is an example of the integration of user innovation (and users) into products and organizations. It raises the question, whether the integration of users and their creative use can be seen as a cooperation or more as a take-over. It raises the question which user innovations are integrated (and labeled as cooperation between producers and users) and if there are rejected, ignored or unsuccessful adaptions made by users. Though not researched at all, these cases of failing innovations (in the sense that they are not integrated by companies and not used by a wider public) may help to understand the mechanisms of the negotiated order in digital fields. One example for the missing integration of user tinkering is the case of Circuit Bending.

\subsection{Stable Segregation: The Case of Circuit Bending}

Circuit Bending can be defined as making sounds and music with electronic toys-normally marketed for and used by little kids - that are modified for this purpose by the benders (Eisewicht \& Pfadenhauer, 2016; Ghazala, 2005). The modification focuses not just on the low voltage circuits inside the plastic toys with the aim to alter the sounds the toy makes, but also on the outer appearance in order to show that it is a so-called "bent" toy or instrument. This includes adding potentiometers, oscillators, pitches, knobs, and switches for manipulating sound and jacks to connect speakers, even to nonelectrical toys (e.g. dolls). Most Circuit Benders modify the inner and outer parts of the toys but leave the outer form in such a way that the original form is still recognizable. Circuit Bending focuses on a tension between inner and outer modification, societal meaning and hacker ethos, electronic modification, sound, and music. Steven R. Hammer (2011) puts it this way: "By leaving a bent instrument in its original casing, adding switches and potentiometers, etc., we're (as Circuit Benders) acknowledging that it was a toy for children at one time, and now it is something different. It is repurposed, it is changed, it is a mutant child of techno-tinkering. It is a rhetorical act, challenging an audience to understand the instrument as both a product of past technology and of the artist's manipulation. This is particularly apparent when Barbie toys are bent and thereafter make these wonderfully dark, violent sounds; pink flowers and those sounds, when juxtaposed, communicate something powerful (however varied) to an audience". 
Circuit Benders present and promote their creations on social media and video platforms and they exchange instructions, support and feedback online. They also meet at workshops and events. Circuit Benders are mostly adults with an interest and knowledge in electronics and music. Their interest can be described as an artisanal (in the modification of said toys) and artistic one (in the use of the bent instruments for sound making). The typical activities of Circuit Benders and the exchange between them are organized around their interest and the shared understanding of Circuit Bending (as a joyful, interesting and meaningful activity). As a group of enthusiasts who share some kind of self-understanding as a community of practice, Circuit Benders are to be seen as an example of posttraditional communitarization (Hitzler, 1998; Pfadenhauer, 2005). Digital media formats enable people to find like-minded others scattered all around the globe (e.g. matrixsynth.com, circuitbenders.co.uk, Reed Ghazala's www.anti-theory.com, www.Absurdity.biz, Getlofi.com or www.chipmusic.org).

Since Circuit Benders are not building their own instruments, they use the commercial products of certain manufacturers (like Fisher-Price, Mattel etc.). Therefore we can describe the relation between Circuit Benders (as some kind of prosumers of bent instruments) and commercial producers of the products that are the basis for the bent instruments. Regarding the focus on commercial products, the exchange of knowledge on specific sites or at certain events and the microculture that is organized around the product centered activities, Circuit Bending shares some characteristics with "brand communities" (Muniz \& O'Guinn, 2001). However, appreciation within the culture of Circuit Benders comes from the individual work put in the bending of the product, rather than the "original" state of the product. Circuit Bending is distinct from other uses of the toys as it is an uncommon (mis-)use by unexpected users. Circuit Benders gain appreciation mostly from other benders, who recognize the artisanal and artistic skill behind the bent toys and enjoy the-more or less otherworldly and disharmonic - sounds as well as the exploration of possibilities for sound making.

Though they are unexpected users by the producers and they use the toys in a manner other than their intended or common purpose, Circuit Bending and Circuit Benders are mostly ignored. Neither do firms comment on the misuse (by encouraging or condemning it) nor do they adapt their products to these kind of users (by advertising the products for Circuit Benders, by designing products for Circuit Bending or by preventing the products from being bent). This is surprising, since producers and brands are often alert to unauthorized hacking activities by users, especially if the hack is not in line with the intended brand image (which is obviously the case e.g. with the aforementioned Barbie dolls). In the next case of Online Poker Tools, we identify an example where the relationship between users and producers is less harmonious and producers are less indifferent towards user modifications.

\subsection{Permanent Confrontation: The Case of Online Poker Tools}

The history of online poker is a conflict-laden one, due to the highly contested kind of data in its core: the hand histories. Hand histories basically are records of player decisions with certain cards at hand. In early days of online poker, the architecture of the poker-clients already allowed the platform owners to track games and analyze them for conspicuous behavior. Hand histories are used as an additional offer that could be requested manually via E-Mail. For advanced players, they are a resource for a so called post-mortem-analysis of one's own play. As time went by, some players with an expertise in using complex databases started to use software in order to archive, analyze and improve their own play. From the growing quantity of self-made tools, a secondary market of analysis tools emerged-alongside the official platforms, their business models, rulesets, and features. These commercial tools included an automatic hand history-request that confronted the major poker platform providers with an increasingly costly situation of having to manage the growing number of requests for hand histories. They reacted by outsourcing, and from that point on, hand histories were saved directly on the player's computer. This decision popularized the extensive collection of hand histories which could be imported into the existing tools.

Specific tracking and analysis tools benefited from the outsourcing-decision and achieved mass popularity. Now, nearly simultaneous data tracking could be combined with instantaneous analysis and graphical visualization. Analysis and tracking tools were appropriated and became an essential part of the game. A black market in other people's hand histories emerged along with this development. The offered sets of data allowed players to have detailed information about totally unknown competitors. Also, professional data miners stepped onto the stage, using enormous server capacities in order to track and sell millions of hands following the claim that "poker is no longer a game of imperfect information". Above all, users can (and do) easily import the purchased data in such game play tools. Shared database tools were appropriated by more and more players, following the assumption that better information about players and their hands increases their own winning rate. The popularity of technologicallyadvanced play drove a major public discourse on the privacy and fairness of online poker. In particular, recreational players (so-called "fishes") who were affected by the unfair advantages of well-informed professionals (so-called "sharks") moved away from the platforms. Economically, the poker platform business model heavily relies on the financial input of recreational players. In order to cope with this imbalance of recreational 
and professional players, various providers responded with countermeasures.

A comparison of a variety provider's terms of use of that time shows a significantly growing list of prohibited tools. In the case of one of the biggest poker companies, the number of prohibited tools rose from five (in 2006) to 87 (in 2013). When users of illegitimate tools were identified, their accounts were suspended immediately and their funds seized by the provider. Linked to this strategy of exclusion, processes of observational adjustments regarding detection and scanning technologies emerged as an additional reaction of the providers. Tracking as well as analyzing software turned out to be the most crucial instrument to combat cheating, poker bots and the use of forbidden tools that had simultaneously grown in number. Faced with a continued loss of recreational players, major providers changed the structure of game play, e.g. by implementing a 30-second sitting-rule in order to fight against those players who used a shared database to identify weaker players. More substantial transformation arose with other counteractions as with introducing anonymized gameplay in order to prevent the personalized tracking of hand histories. Anonymity challenged the whole data mining economy so that a data mining company published a method that provided an option to deanonymize tables, allowing commercial data miners and trackers to work as usual.

\section{Discussion: Variants of Interplay}

Our starting point was to focus on the interactive processes that unfold over time along with different actors' reciprocal activities towards media and technology. We have argued that some of these actors have to be regarded as focal actors because they hold the resources and infrastructures in order to develop, market, and diffuse media. We would argue that also, and in particular, when "market concentration, control, and power struggles" are significantly interlocked with internet companies of today (Dolata, 2017), their entanglement with non-company actors and communities has to be taken into account. With regard to three cases-Wii hacking, Circuit Bending, and online poker tools-we reconstructed three variants of interplay: integration, segregation and permanent confrontation.

Wii-remote-hacks are an example of the variant we describe as integration. They got a lot of attention from scholars and economic enterprises alike (e.g. Lee, 2008, the conference paper by Lee describing his hacks has currently 540 citations on Google Scholar). Rather than ignoring the hacks, organizations adapted solutions made by hackers and employed some of the hackers. The recombinations of common objects function as singularized markers of individual competency. Such actors use media channels for self-presentation and to distribute instructions in order for others to replicate the hacks. In a nutshell, integration is thereby based on an interplay between firms and single-or loosely coupled-actors who can be considered "outlaws of innovation" (Flowers, 2008, p. 180).

In the case of Circuit Bending, on the other hand, the segregation of a community of practice and a commercial manufacturer (and their expected users and types of usage) can be observed. Circuit Bending is based on the appropriation of commercial goods. The application of specific skills constitutes a microculture of its ownwith specific forms of knowledge, do's and don'ts, actions and interactions as well as a sense of a shared identity. The bent instrument becomes a medium as a marker of shared motives, recognized competencies and a sense of togetherness. The object constitutes a binding moment of togetherness. At the same time, distribution media as YouTube or bulletin boards enable Circuit Benders to find like-minded people, to present bent instruments, to discuss, to share appreciation and thereby maintain a sense of belonging. The interplay within a community of practice of the users seems to stabilize their segregation from the official toy-manufacturers. That means, their influence on the officially used products, brands, and economic organizations is almost non-existent.

The rules, features and intended roles of onlinepoker, along with its technological fundament, are in a state of a permanent transformation. Service providers, third party-actors as well as users are constantly engaged in acting out their interests, resulting in an incremental but also fundamental change of the rules, design and security architecture of the platforms over the years. The core driver of this dynamic are those activities thatat least potentially-undermine economic interests and business models on one hand, and the countermeasures of providers on the other. Non-official extensions such as shared database tools did not just flourish seperately from the official poker ecosystem (segregation). They actually interfered with the gameplay as well as with the providers' business interests - this is in contrast with Wiihacking which was used in order to gain technological and economic benefits. Since actors extend the official digital environment, they directly intervene with the core medium of the collective activity and in doing so the very basis of average use for every user is altered. The modifications are communicated within official statements and non-official channels. This flow of information contributes to a panoptical constellation that is composed of reciprocal observations, of steps and follow-up steps. Because companies could not absorb the extensions into the rulesets and the technology, extensions are increasingly counteracted via exclusions, via incremental and radical changes in the media technologies. We characterize this variant of an interplay as permanent confrontation and would argue that it is a symptomatic consequence of the increasing complexity of "digital ecosystems" (Eaton, Elaluf-Calderwood, Sørensen, \& Yoo, 2011, p. 3; Tiwana et al., 2010).

From our presented insights (ref. the summarizing Table 1) we derive the following implications for a systematic approach on acting on media: First of all, acting on 
Table 1. Short summary.

\begin{tabular}{|c|c|c|c|}
\hline characteristics case & Wii hacking & Circuit Bending & Online poker tools \\
\hline role of objects as media & $\begin{array}{l}\text { object as marker of } \\
\text { individual expertize and } \\
\text { paragon for firms }\end{array}$ & $\begin{array}{l}\text { object as marker of shared } \\
\text { motives, competencies and } \\
\text { group identity }\end{array}$ & $\begin{array}{l}\text { object as extended and } \\
\text { modified medium, and as } \\
\text { threat of economic interests }\end{array}$ \\
\hline role of distribution media & $\begin{array}{l}\text { self-presentation and } \\
\text { provided instructions }\end{array}$ & $\begin{array}{l}\text { exchange of knowledge, } \\
\text { recognition, and } \\
\text { communitization }\end{array}$ & $\begin{array}{l}\text { dissemination of } \\
\text { appropriation, reciprocal } \\
\text { observation }\end{array}$ \\
\hline social configuration & $\begin{array}{l}\text { self-promoting outlaw } \\
\text { user and appropriating } \\
\text { firms }\end{array}$ & $\begin{array}{l}\text { self-stabilizing community of } \\
\text { outlaw users and ignoring } \\
\text { firms }\end{array}$ & $\begin{array}{l}\text { outsmarting outlaw users } \\
\text { and counteracting firms }\end{array}$ \\
\hline variant of interplay & integration & segregation & confrontation \\
\hline
\end{tabular}

media is not just about the articulation of ideas or about actors and groups of actors and their visions. It rather is about media-related and mediated interactions and their consequences over time. If situated in complex platforms or socio-technical ecosystems, activities of actors and groups of actors can trigger nearly instantaneous effects that "may cascade in unpredictable ways to alter the structure or health of the ecosystem, or end it entirely" (Tiwana et al., 2010). These present dynamic processes can be analytically described as "feedback loops" (Grenz \& Kirschner, in press; Grenz, Möll, \& Reichertz, 2014; Lash, 2003, p. 50). Such an inherent logic of instability yields parallels with characteristics of modernity as discussed by Scott Lash (2003): Within the "second modernity" the securities and certainties provided by institutionalized ways of doing, role expectations and role-systems erode and become more short-lived and fluid. As a consequence, there is a need to find and create adequate rules. Uncertainty and risk, therefore, are the core characteristics of "reflective judgement" (Lash, 2003 , p. 53). Moreover, second modernity means also mediatized modernity. Uncertainties and risks are further compounded with destabilizing effects that emerge along with pervasive and interconnected technologies (e.g. platforms). They are built on the principle of a permanent input of (new) information as well as technological change: "Complex systems do not simply reproduce. They change. It is the 'chaos' or noise of the unintended consequences that lead to system disequilibrium" (Lash, 2003, p. 50). In this way, social and technological modes of institutionalization are merging, resulting in institutions that are "socio-technical" (Lash, 2003, p. 54). These insights are also backed up by more recent studies in the field of "TechnoScienceSocieties" (Maasen, Dickel, \& Schneider, 2017; see also Couldry \& Hepp, 2017, p. 129).

However, not every actor, nor every group of actors and their activities are "naturally" situated within such complex networks of interconnected technologies and people which can bring about the symptomatic feedback loop-effects. Even if nearly every exotic practice of to- day becomes visible via media's observational capacities (Thompson, 2005), not every unforeseen social activity becomes economically relevant and therefore able to evoke "destabilization" (Lash, 2003, p. 50). Rather, the insights which we present from the aforementioned cases help us to understand and to differentiate between the areas of negotiation that emerge with growing interdependencies. Some arenas are bound to separate communities of outlaws in terms of special interest groups (Circuit Bending) who have their specific audiences and are quite popular when it comes to their visibility via different media channels. Other arenas gather speed at high rates but get commodified and absorbed (Flowers, 2008) with time, becoming essential tools within the fabric of everyday life (Wii hacking). Still, other arenas emerge in regard to what has been called "digital infrastructures", or-within business literature- "digital ecosystems" (Eaton et al., 2011, p. 3; Tiwana et al., 2010). In such constellations, economic interests, media technology, social roles, formal and informal rule sets merge to socio-technical institutions. It is exactly here, in these coalescing areas of modern life, where economic success tends to be permanently confronted with side-effects as unforeseen activities may cause tremendous cascade phenomena (online poker tools).

Nowadays, we have to rethink the question of intention and interest in regard to media change. Within spaces where activities can cause wider effects (e.g. reactions of global companies), acting on media may not be primarily driven by ideology, political agenda or creative competencies. When actions-more or less directlyevoke effects and consequences on a public level, then resonance is a growing motive of mediatized action. Illegitimate activities are not always phenomena that have to be described in relation to costs and benefits. Rather, it is the thrill of such action (Lyng, 1990) developing within more or less anonymous spaces which drives people to open up closed systems, to interfere with official rulesets, to circumvent structures, and to modify media technology. Socio-material resonances may be at the heart of media change because they mark a coming- 
together of the activities of media appropriation and the competition with the "big players".

\section{Acknowledgments}

The authors would like to thank the anonymous reviewers that contributed to the clarification of the arguments outlined in the paper. The publication of the paper was funded by the Open Access Publishing Fund of the University of Vienna.

\section{Conflict of Interests}

The authors declare no conflict of interests.

\section{References}

Barley, S. R. (2008). Coalface institutionalism. In R. Greenwood, C. Oliver, \& K. Sahlin (Eds.), The Sage handbook of organizational institutionalism (pp. 490-515). Thousand Oaks, CA: Sage.

Brown, J. S., \& Hagel, J. (2005). The next frontier of innovation. The McKinsey Quarterly, 3, 83-91.

Burgess, J., \& Green, J. (2009). YouTube: Online video and participatory culture. Cambridge: Polity.

Carroll, J., \& Fidock, J. (2011). Beyond resistance to technology appropriation. In Proceedings of the 44th Hawaii International Conference on System Sciences (pp. 1-9). New York, NY: IEEE.

Chesbrough, H. (2003). Open innovation. The new imperative for creating and profiting from technology. Boston, MA: Harvard Business School Press.

Corbin, J., \& Strauss, A. (1990). Grounded theory research: Procedures, canons, and evaluative criteria. Qualitative Sociology, 12, 3-21.

Couldry, N. (2008). Mediatization or mediation? Alternative understandings of the emergent space of digital storytelling. New Media \& Society, 10, 373-391.

Couldry, N., \& Hepp, A. (2017). The mediated construction of reality. Cambridge, and Malden, MA: Polity Press.

Dix, A. (2007). Designing for appropriation. In Proceedings of the 21st British Human Computer Interaction Group Annual Conference 2007 (pp. 27-30). Swinton: British Computer Society.

Dolata, U. (2017, February). Apple, Amazon, Google, Facebook, Microsoft. Market ConcentrationCompetition-Innovation strategies (SOI Discussion Paper 2017-01). Stuttgart: University of Stuttgart. Retrieved from http://www.uni-stuttgart.de/soz/ oi/publikationen/soi_2017_1_Dolata.Apple.Amazon. Google.Facebook.Microsoft.pdf

Eaton, B., Elaluf-Calderwood, S., Sørensen, C., \& Yoo, Y. (2011). Dynamic structures of control and generativity in digital ecosystem service innovation: The cases of the Apple and Google mobile app stores (Working Paper Series, 183, 1-25). London: London School of Economics and Political Science. Retrieved from http://eprints.Ise.ac.uk/47436
Eisewicht, P., \& Pfadenhauer, M. (2016). Zweckentfremdung als movens von Aneignungskulturen [Misuse as a driver of appropriation cultures]. In D. Keller \& M. Dillschnitter (Eds.), Zweckentfremdung. ,Unsachgemäßer' Gebrauch als kulturelle Praxis [Misuse. 'Improper' use as a cultural practice] (pp. 155-174). Paderborn: Wilhelm Fink.

Fidock, J., \& Carroll, J. (2006). The model of technology appropriation: A lens for understanding systems integration in a defense context. In Proceedings of the Seventeenth Australasian Conference in Information Systems ACIS 2006. Adelaine: University of South Australia.

Flowers, S. (2008). Harnessing the hackers: The emergence and exploitation of outlaw innovation. Research Policy, 37, 177-193.

Ghazala, R. (2005). Circuit Bending: Build your own alien instruments. Indianapolis, IN: Wiley.

Grenz, T. (2014). Digitale Medien und ihre Macher [Digital media and their makers] In T. Grenz \& G. Möll (Eds.), Unter Mediatisierungsdruck. Änderungen und Neuerungen in heterogenen Handlungsfeldern [The pressure of mediatization. Changes and innovations within heterogenous fields of action] (pp. 19-50). Wiesbaden: Springer VS.

Grenz, T., \& Kirschner, H. (in press). Unraveling the app store: Toward an interpretative perspective on tracing. International Journal of Communication.

Grenz, T., Möll, G., \& Reichertz, J. (2014). Zur Strukturierung von Mediatisierungsprozessen. Überlegungen zu einer Theorie der reflexiven Mediatisierung am Beispiel von Poker, Fitness und Rechtsmedizin [Towards structuring mediatization processes]. In F. Krotz, C. Despotovic, \& M. Kruse (Eds.), Die Mediatisierung sozialer Welten: Synergien empirischer Forschung [The mediatization of social worlds: Synergies of empirical research] (pp. 73-91). Wiesbaden: Springer VS.

Hammer, S. R. (2011). Materiality and rhetorics of circuit bending: Rehousing, recasing, and decoration. Patchbaydoor. Retrieved from https://patchbaydoor. wordpress.com/2011/08/04/materiality-and-rhetor ics-of-circuit-bending-rehousing-recasing-and-decora tion

Hepp, A. (2016). Pioneer communities: Collective actors in deep mediatization. Media, Culture \& Society, 38, 918-933.

Hess, D. J. (2005). Technology- and product-oriented movements. Science, Technology \& Human Values, 30, 515-535.

Hitzler, R. (1998). Posttraditionale Vergemeinschaftung [Posttraditional communitarization]. Berliner Debatte INITIAL, 9, 81-98.

Kannengießer, S., \& Kubitschko, S. (2017). Acting on media: Influencing, shaping and (re)configuring the fabric of everyday life. Media and Communication, 5(3), 1-4.

Kirchner, S., \& Beyer, J. (2016). Die Plattformlogik als dig- 
itale Marktordnung [The platform logic as a digital market order]. Zeitschrift für Soziologie, 45, 324-339.

Knoblauch, H. (2017). Die kommunikative Konstruktion der Wirklichkeit [The communicative construction of reality]. Wiesbaden: Springer VS.

Krotz, F. (2017). Explaining the mediatisation approach. Journal of the European Institute for Communication and Culture (Javnost), 24, 103-118.

Kubitschko, S. (2015). The role of hackers in countering surveillance and promoting democracy. Media \& Communication, 3, 77-87.

Lash, S. (2003). Reflexivity as non-linearity. Theory, Culture \& Society, 20, 49-57.

Lawrence, T. B., \& Suddaby, R. (2006). Institutions and institutional work. In S. Clegg, R. Stewart, C. Hardy, T. Lawrence, B. Thomas, \& W. Nord (Eds.), The Sage handbook of organization studies (pp. 215-254). London: Sage.

Lee, J. C. (2008). Hacking the Nintendo Wii remote. IEEE Pervasive Computing, 7(3), 39-45.

Lievrouw, L. A. (2006). Oppositional and activist new media: Remediation, reconfiguration, participation. In Proceedings of the Ninth Participatory Design Conference (pp. 115-124). Trento: Participatory Design.

Liou, W.-K., \& Chang, C.-Y. (2014). Utilizing a low-cost, laser-driven interactive system (LaDIS) to improve learning in developing rural regions. Educational Technology \& Society, 17, 93-107.

Lyng, S. (1990). Edgework: A social psychological analysis of voluntary risk taking. American Journal of Sociology, 95, 851-886.

Maasen, S., Dickel, S., \& Schneider, C. (Eds.). (2017). Sociology of the Sciences Yearbook 2017-Techno ScienceSociety. Book in preparation.

Moran, T. P. (2002). Everyday adaptive design. In Conference proceedings, designing interactive systems (pp. 13-14). London: Proceedings of the 4th Conference on Designing Interactive Systems: Processes, Practices, Methods, and Techniques.

Muniz, A., \& O'Guinn, T. C. (2001). Brand community. Journal of Consumer Research, 27, 412-432.

O'Reilly, T. (2005, September). What is Web 2.0? Design patterns and business models for the next generation of software. Retrieved from http://www.oreilly. com/pub/a/web2/archive/what-is-web-20.html
Parikka, J. (2012). What is media archaeology? Cambridge: Polity.

Pfadenhauer, M. (2005). Ethnography of scenes. Towards a sociological life-world analysis of (post-traditional) community-building. Forum: Qualitative Social Research, 6(3), Art. 43.

Schäfer, M. T. (2009). Participation inside? User activities between design and appropriation. In M. van den Boomen, S. Lammes, A. S. Lehmann, J. Raessens, \& M. T. Schäfer (Eds.), Digital material: Tracing new media in everyday life and technology (pp. 147-158). Amsterdam: Amsterdam University Press.

Schütz, A., \& Luckmann, T. (1973). The structures of the life-world (Vol. 1). Evanston, IL: Northwestern University Press.

Strauss, A. (1993). Continual permutations of action. New York, NY: Aldine de Gruyter.

Thompson, J. B. (2005). The new visibility. Theory, Culture \& Society, 22, 31-51.

Tiwana, A., Konsynski, B., \& Bush, A. A. (2010). Platform evolution: Coevolution of platform architecture, governance, and environmental dynamics. Information Systems Research, 21, 675-687.

van den Boomen, M., Lammes, S., Lehmann, A. S., Raessens, J., \& Schäfer, M. T. (Eds.). (2009). Digital material: Tracing new media in everyday life and technology. Amsterdam: Amsterdam University Press.

Vargo, S. L., \& Lusch, R. F. (2006). Service-dominant logic. What it is, what it is not, what it might be. In S. Vargo \& R. F. Lusch (Eds.), The service-dominant logic of marketing: Dialog, debate, and directions (pp. 43-56). London and New York, NY: Routledge.

Wittke, A., Ebner, M., \& Kröll, C. (2013). Von der Kreidetafel zum Tablet [From the chalk board to the tablet]. In M. Ebner \& S. Schön (Eds.), Lehrbuch für Lernen und Lehren mit Technologien [Textbook for learning and teaching with technologies] (pp. 27-38). Berlin: Epubli.

Yucel, K., Orhan, N., Misirli, G., Bal, G., \& Sahin, Y. G. (2010). An improved interactive whiteboard system. In V. Mahadevan \& G. S. Tomar (Eds.), ICETC 2010 (pp. 148-152). New York, NY: IEEE.

Zittrain, J. (2006). The generative Internet. Harvard Law Review, 119, 1974-2040.

\section{About the Authors}

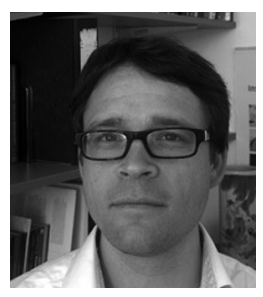

Tilo Grenz is post doc university assistant at the Department of Sociology, University of Vienna, Austria. His research interests include process-oriented approaches for mediatization phenomena and the appropriation of media technology. His current theoretical focus is on reflexive mediatization and specific features of digital materiality as coupled with digital infrastructures. His methodological focus is on the interpretative tracing of media changes. 


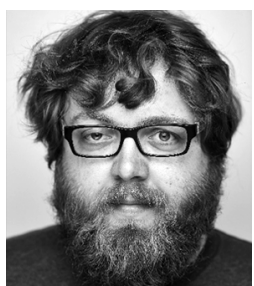

Paul Eisewicht is post doc researcher at the Department of Sociology, TU Dortmund University, Germany. His theoretical interest is focused on motives and modern forms of belonging in the context of individualized and pluralized societies, his research fields include youth scenes, brand communities and consumption practices. His methodological focus is on ethnographic approaches. 